\title{
3,4-Methylenedioxymethamphetamine Increases Affiliative Behaviors in Squirrel Monkeys in a Serotonin 2A Receptor-Dependent Manner
}

\author{
Elizabeth G Pitts', Adelaide R Minerva', Erika B Chandler', Jordan N Kohn', Meghan T Logun', \\ Agnieszka Sulima ${ }^{2}$, Kenner C Rice ${ }^{2}$ and Leonard L Howell*, I,3 \\ 'Yerkes National Primate Research Center, Emory University, Atlanta, GA, USA; '2Drug Design and Synthesis Section, Molecular Targets and \\ Medications Discovery Branch, National Institute on Drug Abuse and the National Institute on Alcohol Abuse and Alcoholism, Bethesda, MD, USA; \\ ${ }^{3}$ Department of Psychiatry and Behavioral Sciences, Emory University, Atlanta, GA, USA
}

\begin{abstract}
3,4-Methylenedioxymethamphetamine (MDMA) increases sociality in humans and animals. Release of serotonin (5-HT) is thought to have an important role in the increase in social behaviors, but the mechanisms underlying these effects are poorly understood. Despite the advantages of nonhuman primate models, no studies have examined the mechanisms of the social effects of MDMA in nonhuman primates. The behavior and vocalizations of four group-housed squirrel monkeys were examined following administration of MDMA, its enantiomers, and methamphetamine. 5-HT receptor antagonists and agonists were given as drug pretreatments. Data were analyzed using linear mixed-effects models. MDMA and its enantiomers increased affiliative social behaviors and vocalizations, whereas methamphetamine had only modest effects on affiliative behaviors. Pretreatment with a $5-\mathrm{HT}_{2 \mathrm{~A}}$ receptor antagonist and a $5-\mathrm{HT}_{2} \mathrm{C}$ receptor agonist attenuated the MDMA-induced increase in social behaviors, while a 5-HT IA receptor antagonist did not alter affiliative vocalizations and increased MDMA-induced social contact. Nonhuman primates show MDMA-specific increases in affiliative social behaviors following MDMA administration, in concordance with human and rodent studies. MDMA-induced increases in social behaviors are 5-HT2A, but not 5-HTIA, receptor dependent. Understanding the neurochemical mechanisms mediating the prosocial effects of MDMA could help in the development of novel therapeutics with the unique social effects of MDMA but fewer of its limitations.

Neuropsychopharmacology (2017) 42, 1962-1971; doi:I0.1038/npp.2017.80; published online 17 May 2017
\end{abstract}

\section{INTRODUCTION}

The amphetamine derivative 3,4-methylenedioxymethamphetamine (MDMA) is the essential active component of the club drug 'ecstasy,' and increased sociability is cited as a main reason for its recreational usage (Sumnall et al, 2006). MDMA increases social interaction, self-reported ratings of social feelings, and the number of social words used in humans, as well as increasing adjacent lying (a passive social interaction) and social conditioned place preference in rodents (see Kamilar-Britt and Bedi, 2015).

Behaviorally active doses of racemic MDMA release monoamines into the synapse (Rietjens et al, 2012). Recreationally and clinically used MDMA is usually a $1: 1$ mixture of enantiomers, although stereoselective disposition increases the ratio of $\mathrm{R}(-)$ MDMA overtime (Fallon et al, 1999). The stereoisomers have different pharmacological

*Correspondence: Dr LL Howell, Yerkes National Primate Research Center, Emory University, 954 Gatewood Road NE, Atlanta, GA 30329, USA, Tel: +| 404727 7786, Fax: + | 404727 1266,

E-mail: Ihowell@emory.edu

Received 2 January 2017; revised 5 April 2017; accepted 16 April 2017; accepted article preview online 20 April 2017 profiles; $\mathrm{S}(+)$ MDMA increases dopamine and serotonin (5-HT), while $\mathrm{R}(-)$ MDMA less potently releases 5-HT but has little effect on dopamine release (Murnane et al, 2010). Additionally, $\mathrm{R}(-)$ MDMA binds to specific receptors (eg, 5- $\mathrm{HT}_{2}$ ) (Lyon et al, 1986). The potency for 5-HT release is greater than other psychostimulants (Rothman et al, 2001), which is thought to mediate the unique subjective profile of racemic MDMA (Liechti et al, 2000a). However, additional mechanisms underlying the prosocial effects of MDMA are not well understood.

Rodent studies indicate that activation of the $5-\mathrm{HT}_{1 \mathrm{~A}}$ receptor may be necessary for MDMA-induced adjacent lying (eg, Thompson et al, 2007). However, human studies using pindolol, a beta-adrenergic antagonist that also partially blocks $5-\mathrm{HT}_{1 \mathrm{~A}}$ receptors, found that $5-\mathrm{HT}_{1 \mathrm{~A}}$ receptors were not necessary for MDMA-induced social feelings or changes in emotional empathy (van Wel et al, 2012; Kuypers et al, 2014).

Another important 5-HT receptor that could have a role in the unique social effects of MDMA is the $5-\mathrm{HT}_{2 \mathrm{~A}}$ receptor. Several of the effects of MDMA are $5-\mathrm{HT}_{2 \mathrm{~A}}$ receptor dependent, including hyperlocomotion (Herin et al, 2005), changes in body temperature (Herin et al, 2005), and striatal 
dopamine overflow (Schmidt et al, 1994). Some human literature supports the role of the $5-\mathrm{HT}_{2 \mathrm{~A}}$ receptor in the social effects of MDMA. Ketanserin, a 5- $\mathrm{HT}_{2 \mathrm{~A} / 2 \mathrm{C}}$ antagonist, blocked MDMA-induced positive affect (van Wel et al, 2012) and emotional excitation but did not decrease the ratings of extroversion or positive mood (Liechti et al, 2000b). The mixed $5-\mathrm{HT}_{2 \mathrm{~A} / 2 \mathrm{C}}$ profile of ketanserin might contribute to the conflicting results, given that $5-\mathrm{HT}_{2 \mathrm{~A}}$ and $5-\mathrm{HT}_{2 \mathrm{C}}$ receptors often have opposing effects on psychostimulantinduced behaviors and dopamine overflow in the striatum (Howell and Cunningham, 2015).

The present study evaluated the social effects of MDMA, its enantiomers, and methamphetamine in squirrel monkeys. Methamphetamine was used to examine the social effects of a similar amphetamine-derivative but with a higher dopamine to 5-HT release profile (Rothman et al, 2001). Additionally, this study examined the receptor pharmacology underlying MDMA-induced social behaviors. Animal experiments allow for the use of novel, and more selective, antagonists to better understand the pharmacological mechanism of the social effects of MDMA. Further, squirrel monkeys have a pharmacokinetic profile for MDMA similar to humans (Mueller et al, 2009), providing considerable translational relevance, given the concern that different pharmacokinetic processing can alter the effects of MDMA (Green et al, 2012). Despite these advantages, only one study has examined the social effects of MDMA in nonhuman primates (Ballesta et al, 2016), and no studies have used nonhuman primates to analyze the mechanisms underlying the social effects of MDMA. Here behavioral and vocal changes were examined following administration of MDMA, its enantiomers, or methamphetamine. Additionally, receptor-specific antagonists were used to investigate the role of the $5-\mathrm{HT}_{2 \mathrm{~A}}$ and $5-\mathrm{HT}_{1 \mathrm{~A}}$ receptors in the social effects of MDMA.

\section{MATERIALS AND METHODS}

\section{Subjects}

Four adult male squirrel monkeys (Saimiri boliviensis) weighing between 800 and $1300 \mathrm{~g}$ and between 11 and 16 years of age were used in all studies. Subjects were group housed in a $1.4 \times 1.8 \times 0.7 \mathrm{~m}^{3}$ cage with access to swings and perches. The colony and laboratory were kept at $\sim 23^{\circ} \mathrm{C}$. Subjects were fed twice daily (monkey chow: Harlan Teklad, Madison, WI; fresh fruits and vegetables), had ad libitum access to water, and received daily enrichment (ie, foraging opportunities and different toys that were changed daily). All subjects had previous exposure to drugs acting on monoaminergic and/or glutamatergic systems (eg, Cooper et al, 2014). However, the last drug exposure for all animals was at least 2 years before the beginning of this study. All studies were conducted in accordance with the National Institute of Health's Guide for the Care and Use of Laboratory Animals, the Association for Accreditation of Laboratory Animals Care, and were approved by the Institutional Animal Care and Use Committee of Emory University.

\section{Experimental Protocol}

For experimental sessions, the home cage was moved to a laboratory room separated from the colony. Subjects were left alone in the laboratory for $2 \mathrm{~h}$ before drug administration to habituate to the environment. All subjects were given the same dose of racemic MDMA (0.03-1.0 mg/kg, i.m.), S(+) or $\mathrm{R}(-)$ MDMA (0.3-3.0 mg/kg, i.m.), methamphetamine (0.01-0.3 mg/kg, i.m.), or sterile saline. Doses of drugs were given in a randomized order with at least 2 days in between drug administrations. Pretreatments with M100907 (M100) (0.1 and $0.3 \mathrm{mg} / \mathrm{kg}$, i.m.), a selective $5-\mathrm{HT}_{2 \mathrm{~A}}$ receptor antagonist (Table 1 ), were administered $1 \mathrm{~h}$ prior to MDMA administration. Pretreatments with WAY163909 (WAY163) (0.03 and $0.3 \mathrm{mg} / \mathrm{kg}$, i.m.), a selective $5-\mathrm{HT}_{2 \mathrm{c}}$ receptor agonist (Table 1), were administered $45 \mathrm{~min}$ prior to MDMA administration. These doses and time frames were chosen because they have been shown previously to affect behavior, neuroendocrine response, and neurotransmitter release following stimulant administration (eg, Fantegrossi et al, 2009). Pretreatments with WAY100635 (WAY100) (0.1 and $0.3 \mathrm{mg} / \mathrm{kg}$, i.m.), a selective $5-\mathrm{HT}_{1 \mathrm{~A}}$ receptor antagonist (Table 1), were administered 20 min prior to MDMA administration. Dose and timing were based on previous studies in marmosets (Harder and Ridley, 2000) and rodents (Thompson et al, 2007). Saline (sterile 0.9\%, i.m.) controls were performed in between drug administration days. Experiments were broken into two testing phases, with baselines collected at the beginning of the experiment and before WAY163 and WAY100 testing. For $1 \mathrm{~h}$ following drug administration, subjects were videotaped (Samsung F90BN HD camcorder, Suwon, South Korea) and vocalizations were recorded (Seinheiser K6 microphone (Wedemark, Germany) on a Focusrite Scarlett $2 \mathrm{i}$ audio interface (High Wycombe, UK) using the Ableton live lite 8 software (Berlin, Germany).

For behavioral outcomes, a reviewer blinded to drug condition watched the video recordings and used a

Table I Binding Affinity (Ki) for 5-HT Receptor Ligands at Various 5-HT, Dopamine, and Adrenergic Receptors

$K_{\mathrm{i}}(\mathrm{nM})$

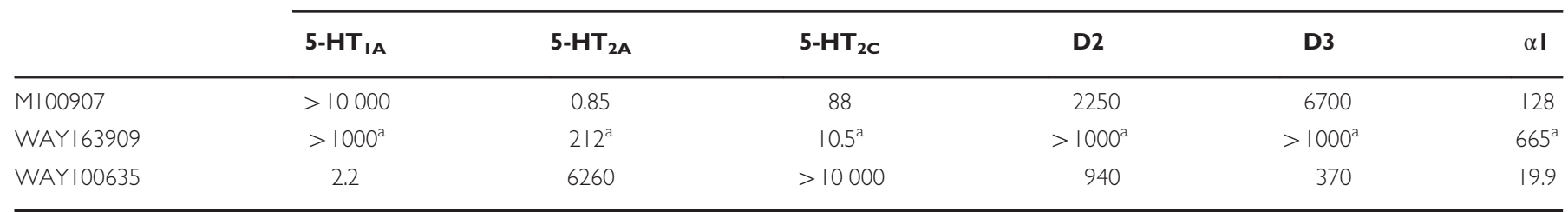

Data from PDSP database: https://kidbdev.med.unc.edu/databases/pdsp.php.

${ }^{\mathrm{a}}$ Dunlop et al, 2005. 
behavioral ethogram to score duration of behaviors (J-Watcher v1.0 software; Sydney, Australia). A single rater, trained to high inter-rater reliability across multiple training videos, scored all videos being compared statistically. The behavioral ethogram used huddling as the main affiliative behavior (squirrel monkeys, unlike other nonhuman primates, do not groom socially; Baldwin and Baldwin, 1981). The ethogram also included duration of activity, aggression (eg, chasing and head grasping), and residual (ie, not performing other scored behaviors) (Hopf et al, 1974). The focal animal scoring technique (Altmann, 1974) was used to assess duration of behaviors. Each monkey was assessed for 5 min within each of three, 20-min blocks across the hourlong observation period (ie, each monkey was scored for 15 total minutes across the hour). The order of scoring was randomized across trials but kept consistent across the three blocks within a single hour session.

Auditory files of vocalizations for the entire group were converted to spectrogram files in the MATLAB software (The MathWorks, Natick, MA) using software customwritten by Sober and Brainard (2009). Vocalizations were distinguished based on shape of spectrogram and classified into one of the three categories. Vocalizations categorized as affiliative were chucks, purrs, and pulsed calls. These call types are associated with huddling, soliciting contact from a partner, or providing important information to the troop, respectively (Jurgens, 1979; Smith et al, 1982). The other two vocalizations were growls, calls commonly observed in connection with threat displays and aggression, and peeps, observed during exploration and after changes in the environment (Winter, 1968; Jurgens, 1979).

\section{Drugs}

Racemic, $\mathrm{S}(+)$, and $\mathrm{R}(-)$ MDMA HCl, methamphetamine $\mathrm{HCl}$ (National Institute on Drug Abuse, Research Technology Branch, Research Triangle Park, NC), and WAY100635 $\mathrm{HCl}$ (N-[2-[4-(2-Methoxyphenyl)-1-piperazinyl]ethyl]-N-2pyridinylcyclohexanecarboxamide maleate salt) (Abcam Biochemicals, Cambridge, MA) were dissolved in $0.9 \%$ sterile physiological saline. M100907 $\mathrm{HCl}((\mathrm{R})-(+)-\alpha-(2,3-$ dimethoxyphenyl)-1-[2-(4-fluorophenyl)ethyl]-4-pipidinemethanol) was a generous gift from Kenner $\mathrm{C}$ Rice, $\mathrm{PhD}$ and was synthesized at the Molecular Targets and Medications Discovery Branch (National Institute on Drug Abuse and National Institute on Alcohol Abuse and Alcoholism at the National Institutes of Health). M100 was dissolved in sterile saline and $1.0 \mathrm{~N}$ hydrochloric acid and returned to a $\mathrm{pH}$ of 5-6. WAY163909 HCl ((7b-R,10a-R)-1,2,3,4,8,9,10,10a-octahydro-7bH-cyclopenta[b][1,4] diazepino $[6,7,1$ hi $]$ indole) was a generous gift from Pfizer Incorporated (New York, $\mathrm{NY}$ ) and was dissolved in a $10 \mathrm{mg} / \mathrm{ml}$ solution of beta cyclodextrin. Doses were calculated from salt weights.

\section{Data Analysis}

The behavioral and vocalization data were analyzed using linear mixed-effects models (LMMs) following $\log (y+1)$ transformation of the dependent variables. This method reliably controls type I error rates and is more parsimonious than generalized linear mixed-effects models (GLMMs) that are often applied to non-Gaussian data when testing for significance of regression coefficients (Warton et al, 2016). We conducted all statistical analyses in $\mathrm{R}$ statistical software (R Core Team, 2014), and LMMs were computed using the lme4 package (Bates et al, 2012). To evaluate the possibility that more complex GLMMs better describe the relationships between dose, behavior, and vocalizations, we also implemented GLMMs with a log-link function (ie, Poisson regression) and compared pseudo-R-squared values between the GLMM and corresponding LMM using the MuMIn package (Barton, 2015). GLMM results did not qualitatively differ from the linear model results and are therefore reported in Supplementary Table S1 instead of the main text.

Behavioral data was modeled in seconds and included dose and bin (within the $1 \mathrm{~h}$ observation period) as fixed effects and controlled for random effects of study subject and testing day. Vocalization data (group-wide frequency) were summed into $6,10-\mathrm{min}$ bins across the $1 \mathrm{~h}$ observation period and were modeled as frequencies (ie, counts), with dose and bin as fixed effects and the random effect of testing day.

As dose-response curves are sometimes non-linear, we also tested for polynomial relationships between drug dosage and behavioral and vocalization responses by re-running each LMM with an orthogonal, second-order polynomial (ie, quadratic) dosage term as a fixed effect. We tested for improvements in fit over the simpler monomial linear models using chi-squared statistics implemented in lme4. When results of the likelihood-ratio test suggested an improved fit for the polynomial models, we tested for significance of the fixed effects and report regression coefficients and $t$-statistics from the polynomial models (Supplementary Table S1).

Model residuals were visually inspected for homoscedasticity, and normality was assessed using the one-sample Komlogorov-Smirnov test to examine deviation of standardized residuals from a theoretical standard normal distribution. Model degrees of freedom (df), $t$-statistics, and $p$-values for fixed effects in LMMs were obtained by using residual maximum likelihood tests with Satterthwaite approximations of df using the lmerTest package (Kuznetsova et al, 2015).

\section{RESULTS}

\section{MDMA and its Enantiomers Increase Affiliative Social Behaviors}

To examine whether MDMA increased affiliative behaviors in nonhuman primates, huddling and activity were scored for $1 \mathrm{~h}$ following drug administration. No aggressive interactions were observed during testing and stereotypies were not quantified, but no adverse effects were seen. MDMA increased huddling $\left(\beta_{\text {dose }}=18.5, t_{330}=9.98\right.$, $p<0.001$; Figure 1a, Supplementary Figure S1A) and decreased activity $\left(\beta_{\text {dose }}=-15.3, t_{330}=-9.32, \quad p<0.001\right)$ (Figure 1b). Both enantiomers of MDMA also significantly increased huddling $\left(\beta_{\text {dose }}=24.9, t_{29}=8.40, p<0.001\right)$ and decreased activity $\left(\beta_{\text {dose }}=-0.96, t_{27}=-7.40, p<0.001\right)$. At lower doses, $\mathrm{S}(+)$ MDMA increased huddling $\left(\beta_{\text {drug } \times \text { dose }}=-55.5, p=t_{125}=-4.23, p<0.001\right)$ and reduced activity levels $\left(\beta_{\text {drug } \times \text { dose }}=-1.25, t_{125}=-4.23, p<0.001\right)$ relative to $\mathrm{R}(-$ ) MDMA (Figure $1 \mathrm{c}-\mathrm{f}$, Supplementary Figure $\mathrm{S} 1 \mathrm{~B}$ and $\mathrm{C})$. In contrast to racemic MDMA and its enantiomers, methamphetamine did not significantly 

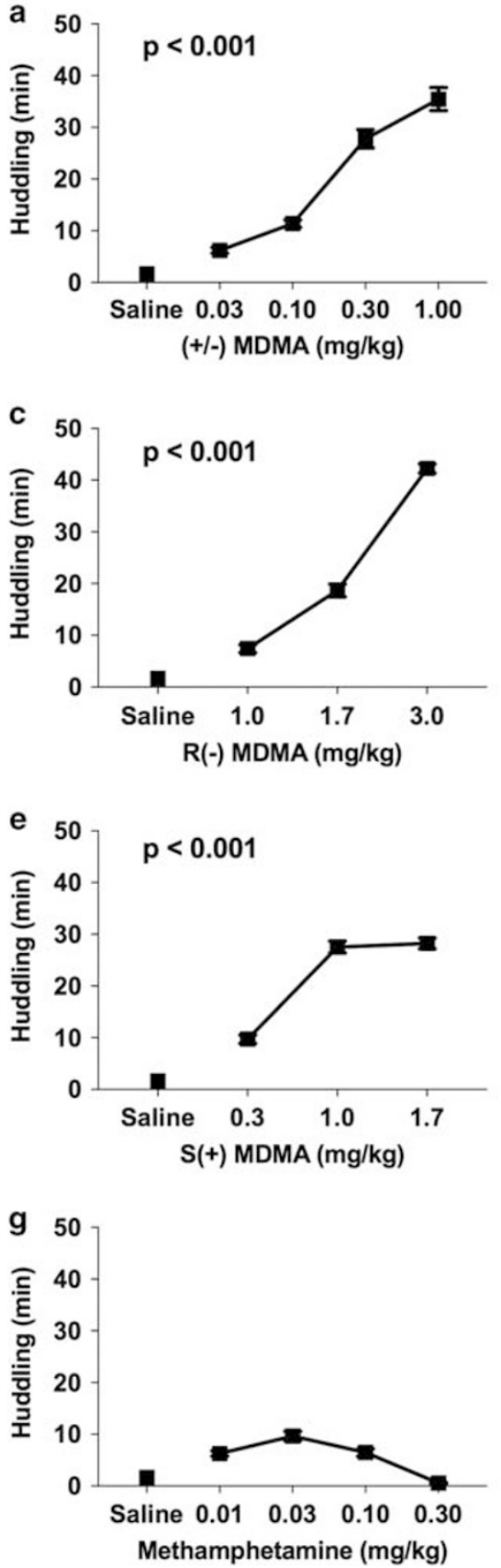
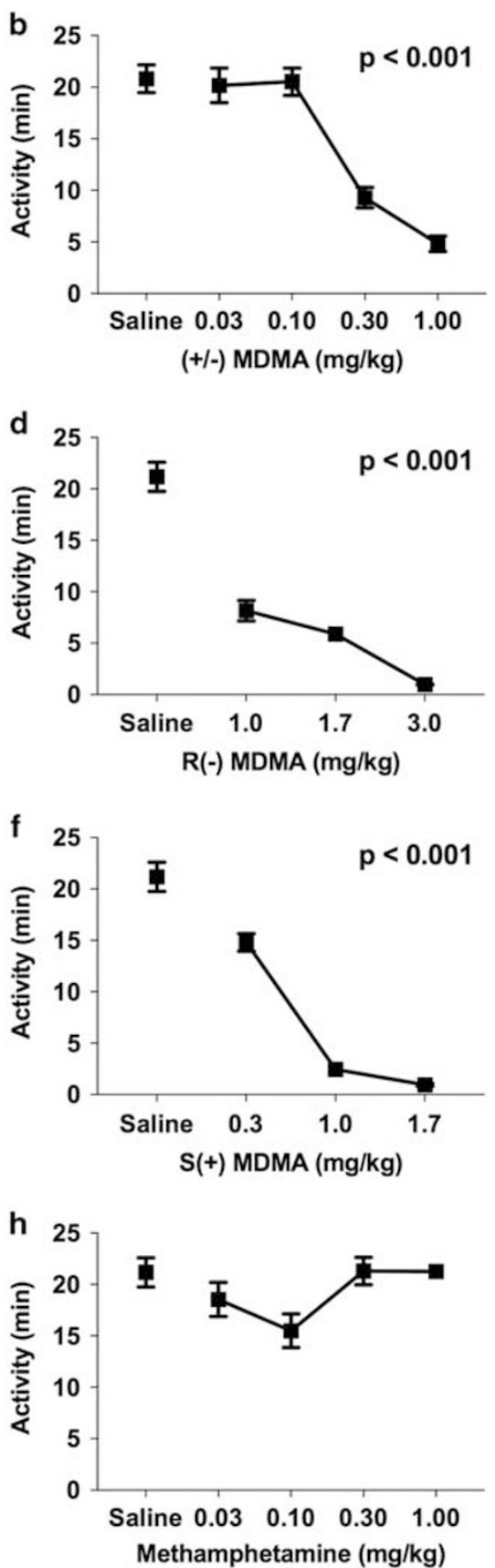

Figure I MDMA and its enantiomers, but not methamphetamine, increase huddling. Average time (in min) spent huddling (a, c, e, and g) and active (b, $d, f$, and h) during I-h observations following drug administration. Collapsed across group of four monkeys. Number of sessions was between 3 and 5 for each dose. Error bars represent SEM for variation between subjects.

increase huddling or change activity levels (Figure $1 \mathrm{~g}$ and $\mathrm{h}$, Supplementary Figure S1D; Supplementary Table S1).

\section{MDMA and its Enantiomers Increase Affiliative Vocalizations}

MDMA increased the number of affiliative vocalizations in the hour following drug administration $\left(\beta_{\text {dose }}=7.79\right.$, $t_{19}=4.77, p<0.001$ ) (Figure 2a). All three types of affiliative vocalizations increased following MDMA administration, with pulsed calls increasing the most from baseline
( 5000\%). Purrs also increased from baseline ( 1500\%) but represent lower total numbers than pulsed calls and chucks (Figure $2 \mathrm{~b}$ ). Both the $\mathrm{R}(-)$ and $\mathrm{S}(+)$ enantiomers of MDMA also significantly increased affiliative calls $\left(\beta_{\text {dose }}=11.4, \quad t_{19}=8.28 p<0.001\right)$, though the $\mathrm{R}(-)$ enantiomer was associated with more affiliative calls at higher doses compared with the $\mathrm{S}(+)$ enantiomer $\left(\beta_{\text {drug } \times \text { dose }}=-27.2, \quad t_{19}=-5.99, \quad p<0.001\right) \quad$ (Figure $2 \mathrm{c}$ and d). In contrast, methamphetamine was not associated with increased affiliative vocalizations (Figure 2e; Supplementary Table S1). 


\section{MDMA and its Enantiomers Affect Other Vocalizations}

Changes to two other main categories of vocalizations, peeps and growls, were also examined following drug administration. MDMA decreased peep call frequency $\left(\beta_{\text {dose }}=-6.47\right.$, $t_{20}=-5.12, \quad p<0.001$; Figure 3a) and increased growl frequency $\left(\beta_{\text {dose }}=5.11, t_{20}=9.85, p<0.001\right.$; Figure $\left.3 b\right)$ during the session. Again, both the $\mathrm{R}(-)$ and $\mathrm{S}(+)$ enantiomers of MDMA decreased peep calls $\left(\beta_{\text {dose }}=-0.46, t_{21}=-2.61\right.$, $p=0.016)$ (Figure $3 \mathrm{c}$ and $\mathrm{e}$ ) and increased growls $\left(\beta_{\text {dose }}=7.24, t_{143}=9.58, p<0.001\right) \quad$ (Figure $3 \mathrm{~d}$ and $\left.\mathrm{f}\right)$. In comparing the potency and efficacy of the two stereoisomers, $\mathrm{S}(+)$ MDMA had stronger effects on peep calls than $\mathrm{R}(-)$ MDMA as dosage increased $\left(\beta_{\text {drug } \times \text { dose }}=-0.88, t_{21}=-2.73\right.$, $p=0.012)$, whereas the $\mathrm{R}(-)$ enantiomer had stronger effects on growls at higher doses $\left(\beta_{\operatorname{drug} \times \text { dose }}=-12.9, t_{143}=-5.15\right.$, $p<0.001)$. Methamphetamine also significantly decreased peep call frequency $\left(\beta_{\text {dose }}=-6.96, t_{17}=-4.20, p<0.001\right.$; Figure $3 \mathrm{~g}$ ) but did not change the frequency of growls emitted (Figure 3h; Supplementary Table S1).

\section{MDMA-Induced Affiliative Behaviors are 5- $\mathrm{HT}_{2 \mathrm{~A}}$, but not 5-HT $1 \mathrm{~A}$, Dependent}

To examine the receptor pharmacology underlying the effects of MDMA on nonhuman primate behaviors and vocalizations, we administered 5-HT receptor antagonists or agonists prior to MDMA administration. M100, a selective $5-\mathrm{HT}_{2 \mathrm{~A}}$ receptor antagonist, blocked MDMA-induced huddling $\quad\left(\beta_{\text {MDMA } \times \text { M100 }}=-23.8, \quad t_{17}=-4.20, \quad p<0.001\right)$ (Figure 4a). M100 trended $(p<0.1)$ toward reducing MDMA-induced affiliative calls $\left(\beta_{\mathrm{MDMA}} \times \mathrm{M} 100=-12.3, t_{23}=\right.$ $-1.90, p=0.071)$ and including the interaction in the model significantly improved model fit (Figure $4 \mathrm{~b}$ ). M100 did not significantly attenuate MDMA-induced decreases in activity levels (Supplementary Figure S2A).

Administration of WAY163, a selective 5- $\mathrm{HT}_{2 \mathrm{C}}$ agonist, also significantly attenuated MDMA-induced huddling $\left(\beta_{\mathrm{WAY} 163 \times \mathrm{MDMA}}=-14.7, \quad t_{190}=-2.11, \quad p=0.036\right.$; Figure 4c) but had no effect on affiliative calls following MDMA administration (Figure 4d; Supplementary Table S2). WAY163 had no significant effect on MDMA-induced decreases in activity (Supplementary Figure S2B).

WAY100, a selective $5-\mathrm{HT}_{1 \mathrm{~A}}$ receptor antagonist, augmented huddling following MDMA administration $\left(\beta_{\mathrm{WAY} 100 \times \mathrm{MDMA}}=14.9, t_{184}=2.34, p=0.020\right.$; Figure $\left.4 \mathrm{e}\right)$ but did not modify MDMA-induced affiliative calls (Figure 4f; Supplementary Table S2). Similar to MDMA, WAY100 administration decreased activity $\left(\beta_{\mathrm{WAY} 100}=-4.74, t_{184}=\right.$ $-3.80, p<0.001$; Supplementary Figure S2C) but did not moderate the effects of MDMA on activity.

Together, these findings suggest that MDMA-induced affiliative behaviors are $5-\mathrm{HT}_{2 \mathrm{~A}}$ receptor, but not $5-\mathrm{HT}_{1 \mathrm{~A}}$, receptor dependent.

\section{Repeated Administration of MDMA Increases Huddling in a Subject with Initially Low MDMA-Induced Social Behaviors}

One animal (177) in the group of four squirrel monkeys initially showed low levels of group huddling following MDMA administration (Figure 1b). However, following repeated, acute administration of racemic MDMA and its enantiomers over the course of the study, 177 developed similar levels of huddling as the other three subjects.
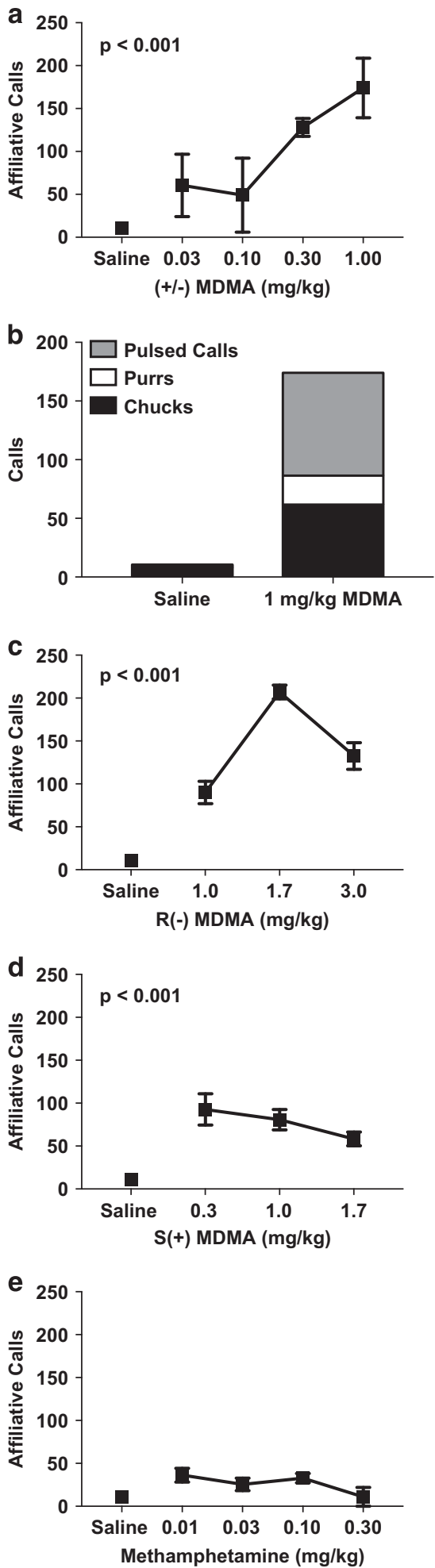

Figure 2 MDMA and its enantiomers, but not methamphetamine, increase affiliative vocalizations. Average number of affiliative calls emitted during the I-h session following drug administration ( $a, c, d$, and e). Affiliative calls broken into three call types (chuck, purr, and pulsed calls) (b). Number of sessions was between 3 and 5 for each dose. Error bars represent SEM for variation across sessions. 

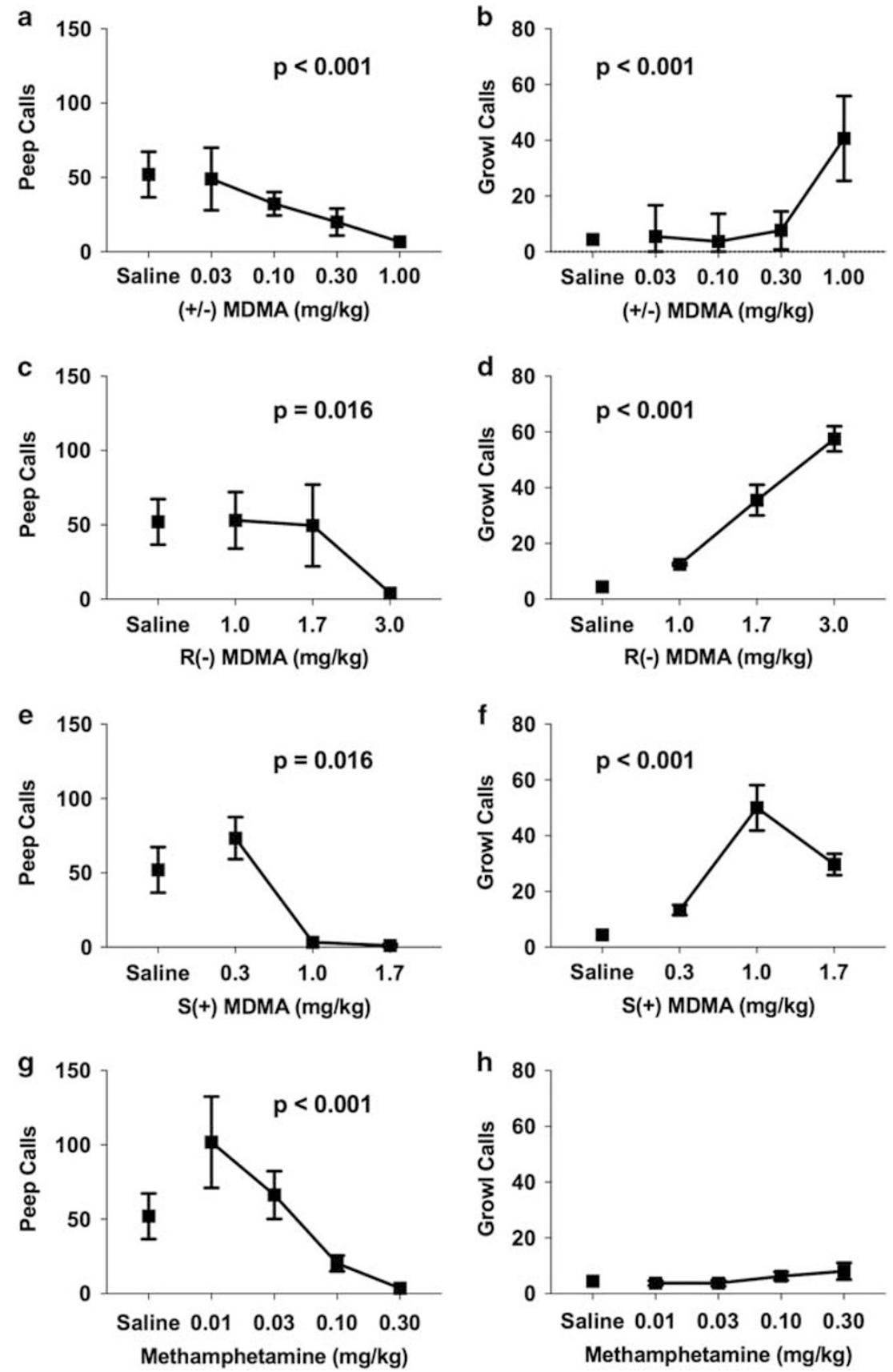

Figure 3 MDMA and its enantiomers decrease peeps and increase growl calls. Average number of peep (a, c, e, and g) and growl (b, d, f, and h) calls emitted during the I-h session following drug administration. Number of sessions was between 3 and 5 for each dose. Error bars represent SEM for variation across sessions.

There was a significant three-way interaction between phase, dose, and subject $\left(F_{3}, \quad 208=3.39, \quad p=0.019\right)$ and comparing the least-squares means between phases within each subject showed a significant increase in the average time spent huddling by 177 between phases (phase 1: $35.8 \pm 32.8 \mathrm{~s}$; phase 2: $202.1 \pm 44.1 \mathrm{~s} ; t_{208}=3.64$, $p=0.002$ ) but not the other three animals (Supplementary Figure S3). This is not a systematic study of the long-term effects of MDMA, but it is interesting given the long-term effects of MDMA in clinical settings (Mithoefer et al, 2013). Future studies could examine the potential long-term social and group effects of MDMA in a more controlled manner.

\section{DISCUSSION}

The aim of the present study was to examine the affiliative social effects of MDMA in socially housed squirrel monkeys and to examine the 5-HT receptor pharmacology underlying MDMA-induced social behaviors. MDMA and its enantiomers dose-dependently increased huddling and the number of affiliative vocalizations emitted by group-housed squirrel 

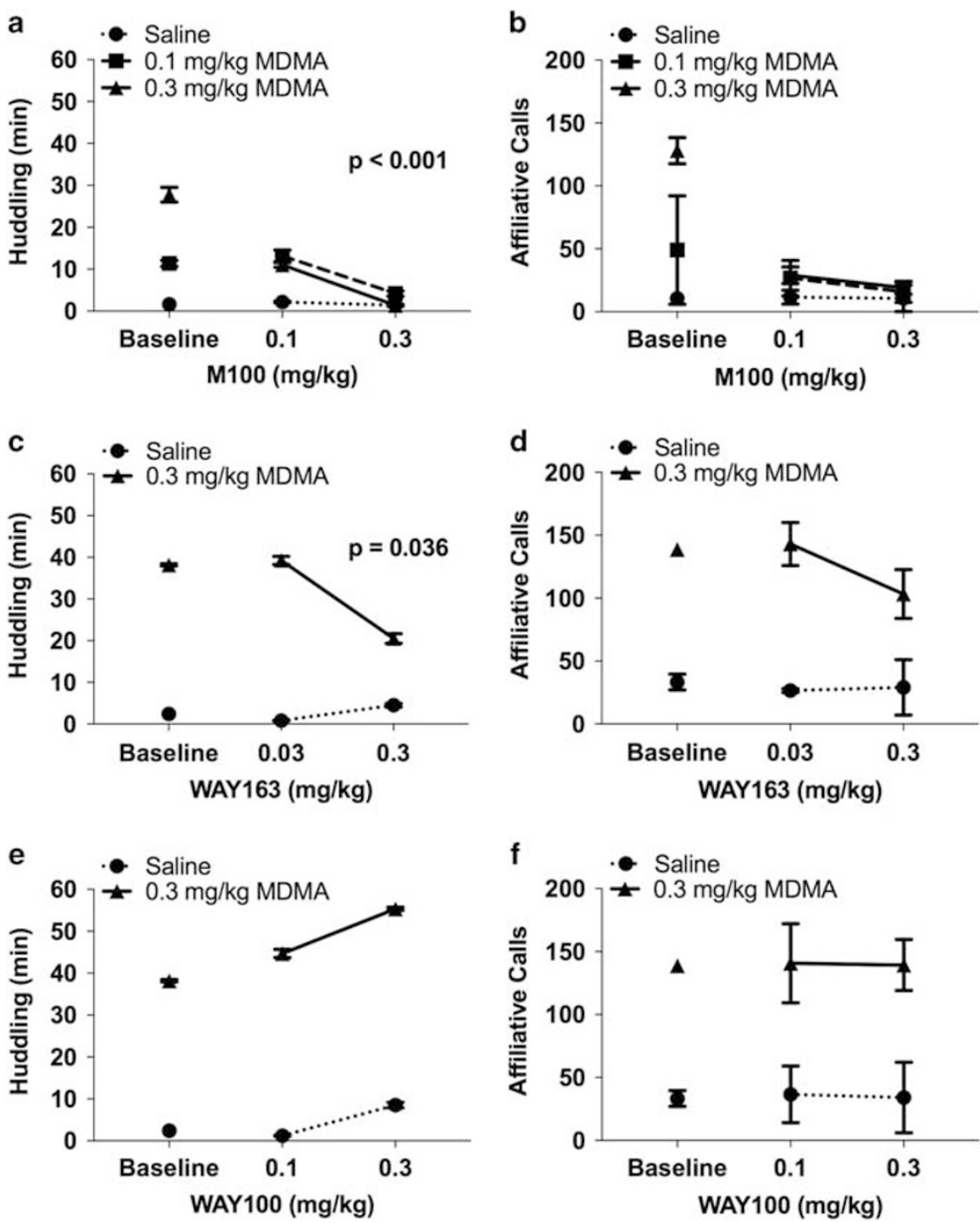

Figure 4 MDMA-induced affiliative behaviors are 5- $\mathrm{HT}_{2 \mathrm{~A}}$ receptor-dependent. Average time (in min) spent huddling (a, c, and e) and average number of affiliative calls (b, d, and f) during I-h observations following drug administration. MI00907 (MI00) is a selective 5-HT2A receptor antagonist (a and b). WAYI63909 (WAYI63) is a selective 5-HT 2C receptor agonist (c and d). WAYI00635 (WAYI00) is a selective 5-HT IA receptor antagonist (e and f). Number of sessions was between 2 and 5 for each dose. Error bars represent SEM for variation between subjects (huddling) or across sessions (vocalizations).

monkeys. Additionally, pretreatments with a $5-\mathrm{HT}_{2 \mathrm{~A}}$ receptor antagonist or a $5-\mathrm{HT}_{2 \mathrm{C}}$ receptor agonist attenuated MDMA-induced huddling and a $5-\mathrm{HT}_{1 \mathrm{~A}}$ receptor antagonist increased MDMA-induced huddling but did not change affiliative vocalizations.

Studies have shown that MDMA increases feelings of sociability in humans and increases social interaction in rodents (Kamilar-Britt and Bedi, 2015). The only study to examine the social effects of MDMA in nonhuman primates also found that MDMA increases social grooming in longtailed macaques (Ballesta et al, 2016). In concordance with this research, the present experiments found that MDMA significantly increases huddling and affiliative calls in squirrel monkeys.

MDMA also increased growl calls, vocalizations usually connected with aggression (Jurgens, 1979). This was unexpected given that MDMA decreases aggression in other animal models (Kamilar-Britt and Bedi, 2015). No aggressive behaviors or other aggressive calls were seen and growl calls, when they occur with chucks, have been seen during huddling (Winter, 1968). This suggests that growls are not exclusively aggressive and may not be indicating aggression in this context, although further studies are necessary.

In contrast with the behavioral changes following MDMA administration, methamphetamine did not significantly increase huddling or affiliative vocalizations. These findings support the unique, robust social effects of MDMA and the use of group-housed squirrel monkeys to further examine those social effects and the underlying mechanisms of MDMA. One limitation of our study was that vocalizations were examined by group, making it impossible to determine if all subjects drove the increase in affiliative vocalizations equally. Future studies could separate calls by subject in order to examine individual differences in MDMA-induced vocalizations. The effects of MDMA in female and juvenile group-housed squirrel monkeys should also be examined to determine whether sex and age have a role in MDMAinduced social behaviors.

Interestingly, despite its structural similarity to psychostimulant compounds, MDMA significantly decreased activity 
in nonhuman primates. This finding supports other studies showing decreased activity levels following MDMA (Crean et al, 2006) and no stimulant effects on operant behavior (Fantegrossi et al, 2009). The present study's group-housing design might enhance changes in activity levels as animals switch allocation of behavior from non-social activity toward affiliative social behaviors. Another interpretation, however, could be that increases in huddling are driven by decreases in locomotion. Previous research supports the conclusion that huddling is independent of locomotor effects following drug administration. Drugs that decrease locomotion do not reliably increase huddling (Miczek et al, 1981) and the effects of stimulants on locomotion and social behaviors are not mediated by the same mechanisms (Miczek and Yoshimura, 1982). This is further supported by our findings showing dissociation between the effects of 5-HT receptor ligands on MDMA-induced huddling and locomotion.

In the present study, pretreatment with M100, a selective 5- $\mathrm{HT}_{2 \mathrm{~A}}$ receptor antagonist, blocked MDMA-induced affiliative social behaviors. Antagonism of $5-\mathrm{HT}_{2 \mathrm{~A}}$ receptors blocks MDMA-induced striatal dopamine overflow (Schmidt et al, 1994). A potential role of 5-HT-mediated striatal dopamine release in the social effects of MDMA is supported by results indicating that pretreatment with WAY163, a 5- $\mathrm{HT}_{2 \mathrm{C}}$ receptor agonist, also decreases MDMA-induced huddling, because $5-\mathrm{HT}_{2 \mathrm{C}}$ receptor activation decreases striatal dopamine release (Howell and Cunningham, 2015). Additionally, the $5-\mathrm{HT}_{2 \mathrm{~A}}$ receptor is expressed extensively throughout the amygdala (Bombardi and Di Giovanni, 2013) and reduces amygdala-dependent reactivity and anxietyrelated behaviors (Weisstaub et al, 2006; Fisher et al, 2009). Given the model that MDMA produces a valence-specific shift in response to social cues, with an increase in recognition of positive social signals and a decrease in response and recognition of negative ones (Kamilar-Britt and Bedi, 2015), the striatal and amygdalar effects of $5-\mathrm{HT}_{2 \mathrm{~A}}$ receptor activation provide a potential mechanism by which $5-\mathrm{HT}_{2 \mathrm{~A}}$ receptors could mediate increased sociality following MDMA.

One potential caveat with the present study is that MDMA has pronounced effects on body temperature (eg, Banks et al, 2007) and antagonism of the $5-\mathrm{HT}_{2 \mathrm{~A}}$ receptor attenuates MDMA-induced changes in body temperature in rodents (Herin et al, 2005) and humans (Liechti et al, 2000b). The temperature of the laboratory (near an ambient temperature in which MDMA administration did not change body temperature in nonhuman primates; Banks et al, 2007) and correlation between affiliative vocalizations and huddling following MDMA (Supplementary Figure S4A) suggest the findings are not driven by changes in body temperature. Additionally, methamphetamine stimulates even more pronounced changes in body temperature (Crean et al, 2006) but did not induce a similar increase in huddling.

The $5-\mathrm{HT}_{1 \mathrm{~A}}$ receptor is also thought to have a role in the social effects of MDMA. In rodents, 5- $\mathrm{HT}_{1 \mathrm{~A}}$ receptor stimulation is necessary for MDMA-induced increases in adjacent lying and oxytocin release (Thompson et al, 2007) and activation of oxytocin neurons (Hunt et al, 2011). Further, one study showed positive correlation between plasma oxytocin and social ratings in the laboratory (Dumont et al, 2009). Counter to these findings, pretreatment with WAY100, a selective $5-\mathrm{HT}_{1 \mathrm{~A}}$ receptor antagonist, increased huddling following MDMA administration and did not affect MDMA-induced vocalizations. Future studies using a wider range of doses of WAY100 and/or $5-\mathrm{HT}_{1 \mathrm{~A}}$ agonists could provide more definitive evidence on the role of the $5-\mathrm{HT}_{1 \mathrm{~A}}$ receptor in social behaviors.

The present study supports evidence in the human literature showing that blocking $5-\mathrm{HT}_{1 \mathrm{~A}}$ receptors does not change increases in self-reported ratings of sociality or emotional empathy following MDMA (van Wel et al, 2012; Kuypers et al, 2014) and null correlations between plasma oxytocin and social feelings (eg, Kuypers et al, 2014). The enhancement of MDMA-induced huddling could have been driven by antagonism of $5-\mathrm{HT}_{1 \mathrm{~A}}$ autoreceptors, driving an additional increase in 5- $\mathrm{HT}$ release. $5-\mathrm{HT}_{1 \mathrm{~A}}$ receptor antagonism potentiates 5 -HT release following administration of selective serotonin reuptake inhibitors (SSRIs) (Hjorth, 1993). Administration of an SSRI increases body contact and grooming behaviors in cynomolgous macaques (Shively et al, 2014), indicating that 5-HT release alone can increase social contact in nonhuman primates. However, further studies are needed to confirm that $5-\mathrm{HT}_{1 \mathrm{~A}}$ receptor antagonism is enhancing MDMA-induced huddling by blunting autoreceptor feedback.

We propose a model for the unique social effects of MDMA, in which 5-HT release, combined with receptorselective direct agonist effects, enhances sociality. In this model, 5-HT release alone can enhance some social behaviors (as seen with increased body contact following SSRI administration; Shively et al, 2014), but the addition of receptor-selective activation enhances these social effects, leading to the unique and robust social behavior caused by MDMA. This model is supported by the dissociation between huddling and affiliative vocalizations following $5-\mathrm{HT}_{1 \mathrm{~A}}$ receptor antagonism, with additional 5-HT release increasing huddling but not affecting affiliative vocalizations. The differing magnitude of effects of the MDMA enantiomers also provides support for the above model. The $\mathrm{S}(+)$ enantiomer is a potent releaser of 5-HT and dopamine, while the $\mathrm{R}(-)$ enantiomer releases less $5-\mathrm{HT}$ and is ineffective in releasing dopamine (Acquas et al, 2007; Murnane et al, 2010) but binds to the $5-\mathrm{HT}_{2}$ receptor (Lyon et al, 1986). S(+) increases huddling more strongly than $\mathrm{R}(-)$ at the same dose, as expected given its more potent release of 5-HT. However, in contrast with its more potent monoamine releasing effects, $\mathrm{S}(+)$ is less effective at eliciting affiliative vocalizations at higher doses than $\mathrm{R}(-)$. Accordingly, the enhanced social effects of $\mathrm{R}(-)$ MDMA are possibly caused by the combination of 5 -HT release and receptor-selective direct agonism. Future studies could examine this model more directly by co-administering $\mathrm{S}(+)$ MDMA or a $5-\mathrm{HT}$ releaser with 5-HT receptor agonists (eg, DOI) and by further studying the role of agonism at other receptor types, such as adrenergic or dopaminergic receptors, in the effects of both enantiomers.

MDMA is currently being evaluated as a therapeutic adjunct for the treatment of PTSD (Mithoefer et al, 2011, 2013). MDMA-assisted psychotherapy sessions may produce long-term decreases in PTSD symptoms in treatmentresistant patients (Mithoefer et al, 2013). An increase in therapeutic alliance from increased sociality and openness following MDMA is thought to have a role in the therapeutic potential of MDMA (Mithoefer et al, 2011). However, there 
are still concerns about the potential neurotoxicity and abuse potential that limit its clinical appeal (Rietjens et al, 2012). Understanding the neuropharmacological mechanisms of the prosocial effects of MDMA could allow for the development of novel therapeutics that specifically target social behavior, while limiting abuse potential, toxicity, and other side effects, which may be especially advantageous in vulnerable clinical populations. The evidence that $\mathrm{R}(-)$ MDMA increases social behaviors to a level similar to racemic MDMA, without causing large amounts of striatal dopamine release (Acquas et al, 2007; Murnane et al, 2010) or inducing neurotoxic effects (Frau et al, 2013), provides a rationale for its potential advantage in therapeutic settings.

\section{FUNDING AND DISCLOSURE}

This research was supported by P51OD11132 (Yerkes National Primate Research Center) and DA 012514 and DA 031246 (to LLH). A portion of this work was supported by the NIH Intramural Research Programs of the National Institute on Drug Abuse and the National Institute of Alcohol Abuse and Alcoholism. The authors declare no conflict of interest.

\section{ACKNOWLEDGMENTS}

Special thanks to the technicians Juliet Brown and Mi Zhou and to Sam Sober, PhD for use of his MATLAB software.

\section{REFERENCES}

Acquas E, Pisanu A, Spiga S, Plumitallo A, Zernig G, Di Chiara G (2007). Differential effects of intravenous R,S-(+/-)-3,4-methylenedioxymethamphetamine (MDMA, Ecstasy) and its S(+)- and R (-)-enantiomers on dopamine transmission and extracellular signal regulated kinase phosphorylation (pERK) in the rat nucleus accumbens shell and core. J Neurochem 102: 121-132.

Altmann J (1974). Observational study of behavior: sampling methods. Behaviour 49: 227-267.

Baldwin J, Baldwin J (1981). The squirrel monkeys, genus Saimiri. In: Coimbra-Filho AF, Mittermeier RA (eds). Ecology and Behavior of Neotropical Primates, Vol 1. Academia Brasileira de Ciências: Rio de Janeiro, Brazil, pp 277-330.

Ballesta S, Reymond G, Pozzobon M, Duhamel JR (2016). Effects of MDMA injections on the behavior of socially-housed long-tailed macaques (Macaca fascicularis). PLoS ONE 11: e0147136.

Banks ML, Sprague JE, Kisor DF, Czoty PW, Nichols DE, Nader MA (2007). Ambient temperature effects on 3,4-methylenedioxymethamphetamine-induced thermodysregulation and pharmacokinetics in male monkeys. Drug Metab Dispos 35: 1840-1845.

Barton K (2015). MuMIn: multi-model inference. R package version 1.13.4 http://CRAN.R-project.org/package = MuMIn.

Bates D, Maechler M, Bolker B (2012). lme4: linear mixed-effects models using S4 classes http://CRAN.R-project.org/package $=$ lme4.

Bombardi C, Di Giovanni G (2013). Functional anatomy of 5-HT2A receptors in the amygdala and hippocampal complex: relevance to memory functions. Exp Brain Res 230: 427-439.

Cooper DA, Kimmel HL, Manvich DF, Schmidt KT, Weinshenker D, Howell LL (2014). Effects of pharmacologic dopamine beta-hydroxylase inhibition on cocaine-induced reinstatement and dopamine neurochemistry in squirrel monkeys. J Pharmacol Exp Ther 350: 144-152.
Crean RD, Davis SA, Von Huben SN, Lay CC, Katner SN, Taffe MA (2006). Effects of (+/-)3,4-methylenedioxymethamphetamine, (+/-)3,4-methylenedioxyamphetamine and methamphetamine on temperature and activity in rhesus macaques. Neuroscience 142: $515-525$.

Dumont GJ, Sweep FC, van der Steen R, Hermsen R, Donders AR, Touw DJ et al (2009). Increased oxytocin concentrations and prosocial feelings in humans after ecstasy (3,4-methylenedioxymethamphetamine) administration. Soc Neurosci 4: 359-366.

Dunlop J, Sabb AL, Mazandarani H, Zhang J, Kalgaonker S, Shukhina E et al (2005). WAY-163909 [(7bR, 10aR)$1,2,3,4,8,9,10,10 \mathrm{a}$-octahydro-7bH-cyclopenta-[b][1,4]diazepino $[6,7,1$ hi] indol e], a novel 5-hydroxytryptamine 2C receptorselective agonist with anorectic activity. J Pharmacol Exp Ther 313: 862-869.

Fallon JK, Kicman AT, Henry JA, Milligan PJ, Cowan DA, Hutt AJ (1999). Stereospecific analysis and enantiomeric disposition of 3, 4-methylenedioxymethamphetamine (Ecstasy) in humans. Clin Chem 45: 1058-1069.

Fantegrossi WE, Bauzo RM, Manvich DM, Morales JC, Votaw JR, Goodman MM et al (2009). Role of dopamine transporters in the behavioral effects of 3,4-methylenedioxymethamphetamine (MDMA) in nonhuman primates. Psychopharmacology 205: 337-347.

Fisher PM, Meltzer CC, Price JC, Coleman RL, Ziolko SK, Becker C et al (2009). Medial prefrontal cortex 5-HT(2A) density is correlated with amygdala reactivity, response habituation, and functional coupling. Cereb Cortex 19: 2499-2507.

Frau L, Simola N, Plumitallo A, Morelli M (2013). Microglial and astroglial activation by 3,4-methylenedioxymethamphetamine (MDMA) in mice depends on $\mathrm{S}(+)$ enantiomer and is associated with an increase in body temperature and motility. $J$ Neurochem 124: $69-78$.

Green AR, King MV, Shortall SE, Fone KC (2012). Lost in translation: preclinical studies on 3,4-methylenedioxymethamphetamine provide information on mechanisms of action, but do not allow accurate prediction of adverse events in humans. $\mathrm{Br} J$ Pharmacol 166: 1523-1536.

Harder JA, Ridley RM (2000). The 5-HT1A antagonist, WAY 100 635, alleviates cognitive impairments induced by dizocilpine (MK-801) in monkeys. Neuropharmacology 39: 547-552.

Herin DV, Liu S, Ullrich T, Rice KC, Cunningham KA (2005). Role of the serotonin 5-HT2A receptor in the hyperlocomotive and hyperthermic effects of (+)-3,4-methylenedioxymethamphetamine. Psychopharmacology 178: 505-513.

Hjorth S (1993). Serotonin 5-HT1A autoreceptor blockade potentiates the ability of the 5-HT reuptake inhibitor citalopram to increase nerve terminal output of 5-HT in vivo: a microdialysis study. J Neurochem 60: 776-779.

Hopf S, Hartmann-Wiesner E, Kuhlmorgen B, Mayer S (1974). The behavioral repertoire of the squirrel monkey (Saimiri). Folia Primatol 21: 225-249.

Howell LL, Cunningham KA (2015). Serotonin 5-HT2 receptor interactions with dopamine function: implications for therapeutics in cocaine use disorder. Pharmacol Rev 67: 176-197.

Hunt GE, McGregor IS, Cornish JL, Callaghan PD (2011). MDMAinduced c-Fos expression in oxytocin-containing neurons is blocked by pretreatment with the 5-HT-1A receptor antagonist WAY 100635. Brain Res Bull 86: 65-73.

Jurgens U (1979). Vocalization as an emotional indicator. A neuroethological study in the squirrel monkey. Behaviour 69: 88-117.

Kamilar-Britt P, Bedi G (2015). The prosocial effects of 3, 4-methylenedioxymethamphetamine (MDMA): controlled studies in humans and laboratory animals. Neurosci Biobehav Rev 57: 433-446.

Kuypers KP, de la Torre R, Farre M, Yubero-Lahoz S, Dziobek I, Van den Bos W et al (2014). No evidence that MDMA-induced 
enhancement of emotional empathy is related to peripheral oxytocin levels or 5-HT1a receptor activation. PLOS ONE 9: e100719.

Kuznetsova A, Brockhoff PB, Christensen RHB (2015). Package 'ImerTest'. $R$ Package Version 2.0-29.

Liechti ME, Baumann C, Gamma A, Vollenweider FX (2000a). Acute psychological effects of 3,4-methylenedioxymethamphetamine (MDMA, 'Ecstasy') are attenuated by the serotonin uptake inhibitor citalopram. Neuropsychopharmacology 22: 513-521.

Liechti ME, Saur MR, Gamma A, Hell D, Vollenweider FX (2000b). Psychological and physiological effects of MDMA ('Ecstasy') after pretreatment with the 5-HT(2) antagonist ketanserin in healthy humans. Neuropsychopharmacology 23: 396-404.

Lyon RA, Glennon RA, Titeler M (1986). 3,4-Methylenedioxymethamphetamine (MDMA): stereoselective interactions at brain 5-HT1 and 5-HT2 receptors. Psychopharmacology 88: $525-526$

Miczek KA, Woolley J, Schlisserman S, Yoshimura H (1981). Analysis of amphetamine effects on agonistic and affiliative behavior in squirrel monkeys (Saimiri sciureus). Pharmacol Biochem Behav 14(Suppl 1): 103-107.

Miczek KA, Yoshimura H (1982). Disruption of primate social behavior by d-amphetamine and cocaine: differential antagonism by antipsychotics. Psychopharmacology (Berl) 76: 163-171.

Mithoefer MC, Wagner MT, Mithoefer AT, Jerome L, Doblin R (2011). The safety and efficacy of $\{+/-\} 3,4$-methylenedioxymethamphetamine-assisted psychotherapy in subjects with chronic, treatment-resistant posttraumatic stress disorder: the first randomized controlled pilot study. J Psychopharmacol 25: 439-452.

Mithoefer MC, Wagner MT, Mithoefer AT, Jerome L, Martin SF, Yazar-Klosinski B et al (2013). Durability of improvement in post-traumatic stress disorder symptoms and absence of harmful effects or drug dependency after 3,4-methylenedioxymethamphetamine-assisted psychotherapy: a prospective long-term followup study. J Psychopharmacol 27: 28-39.

Mueller M, Peters FT, Huestis MA, Ricaurte GA, Maurer HH (2009). Simultaneous liquid chromatographic-electrospray ionization mass spectrometric quantification of 3,4-methylenedioxymethamphetamine (MDMA, Ecstasy) and its metabolites 3,4dihydroxymethamphetamine, 4-hydroxy-3-methoxymethamphetamine and 3,4-methylenedioxyamphetamine in squirrel monkey and human plasma after acidic conjugate cleavage. Forensic Sci Int 184: 64-68.

Murnane KS, Fantegrossi WE, Godfrey JR, Banks ML, Howell LL (2010). Endocrine and neurochemical effects of 3, 4-methylenedioxymethamphetamine and its stereoisomers in rhesus monkeys. J Pharmacol Exp Ther 334: 642-650.

$\mathrm{R}$ Core Team (2014). $R$ : a language and environment for statistical computing. R Foundation for Statistical Computing: Vienna, Austria. http://www.R-project.org/.

Rietjens SJ, Hondebrink L, Westerink RH, Meulenbelt J (2012). Pharmacokinetics and pharmacodynamics of 3,4-methylenedioxymethamphetamine (MDMA): interindividual differences due to polymorphisms and drug-drug interactions. Crit Rev Toxicol 42: 854-876.

Rothman RB, Baumann MH, Dersch CM, Romero DV, Rice KC, Carroll FI et al (2001). Amphetamine-type central nervous system stimulants release norepinephrine more potently than they release dopamine and serotonin. Synapse 39: 32-41.

Schmidt CJ, Sullivan CK, Fadayel GM (1994). Blockade of striatal 5-hydroxytryptamine2 receptors reduces the increase in extracellular concentrations of dopamine produced by the amphetamine analogue 3,4-methylenedioxymethamphetamine. J Neurochem 62: 1382-1389.

Shively CA, Register TC, Higley JD, Willard SL (2014). Sertraline effects on cerebrospinal fluid monoamines and species-typical socioemotional behavior of female cynomolgus monkeys. Psychopharmacology 231: 1409-1416.

Smith HJ, Newman JD, Symmes D (1982). Vocal concomitants of affiliative behavior. In: Brown, Petersen, Snowden (eds). Primate Communication. Cambridge University Press: Cambridge, UK.

Sober SJ, Brainard MS (2009). Adult birdsong is actively maintained by error correction. Nat Neurosci 12: 927-931.

Sumnall HR, Cole JC, Jerome L (2006). The varieties of ecstatic experience: an exploration of the subjective experiences of ecstasy. J Psychopharmacol 20: 670-682.

Thompson MR, Callaghan PD, Hunt GE, Cornish JL, McGregor IS (2007). A role for oxytocin and 5-HT(1A) receptors in the prosocial effects of 3,4 methylenedioxymethamphetamine ('ecstasy'). Neuroscience 146: 509-514.

van Wel JH, Kuypers KP, Theunissen EL, Bosker WM, Bakker K, Ramaekers JG (2012). Effects of acute MDMA intoxication on mood and impulsivity: role of the 5-HT2 and 5-HT1 receptors. PLoS ONE 7: e40187.

Warton DI, Lyons M, Stoklosa J, Ives AR (2016). Three points to consider when choosing a LM or GLM test for count data. Methods Ecol Evol 7: 882-890.

Weisstaub NV, Zhou M, Lira A, Lambe E, Gonzalez-Maeso J, Hornung JP et al (2006). Cortical 5-HT2A receptor signaling modulates anxiety-like behaviors in mice. Science 313: 536-540.

Winter P (1968). Special communication in the squirrel monkey. In: Rosenblum C (eds). The Squirrel Monkey. Academic Press: New York, USA.

Supplementary Information accompanies the paper on the Neuropsychopharmacology website (http://www.nature.com/npp) 